\title{
Synthesis of Oligo(oxyethylene) Methacrylate-ended Poly(n-hexyl isocyanate) Rodlike Macromonomers and Their Radical Copolymerization Behavior with Methyl Methacrylate
}

\author{
By Le Thi Ngoc LIEN, Moriya KIKUCHI, Atsushi NARUMI, \\ Katsutoshi NAGAI, and Seigou KAWAGUCHI
}

\begin{abstract}
A series of novel poly( $n$-hexyl isocyanate) (PHIC) rodlike macromonomers having an $\alpha$-methacryloyloxyoligo(oxyethylene) group and an $\omega$-acetyl group (MA-EO ${ }_{m}$-HIC- $n$-Ac, where $m$ and $n$ are the degrees of polymerization of oxyethylene (EO) and HIC, respectively) have been prepared. They were prepared by living coordination polymerization of HIC using corresponding titanium(IV) alkoxide complexes as an initiator in $\mathrm{CH}_{2} \mathrm{Cl}_{2}$ at room temperature, followed by termination with acetic anhydride as a terminator in the presence of $\mathrm{BF}_{3} \mathrm{OEt}_{2}$ as a Lewis acid. The radical copolymerization behavior of MA$\mathrm{EO}_{m}$-HIC- $n$-Ac $\left(\mathrm{M}_{2}\right)$ with methyl methacrylate (MMA) $\left(\mathrm{M}_{1}\right)$ in benzene at $60^{\circ} \mathrm{C}$ has thoroughly been investigated in order to evaluate an effect of a flexible oligo(oxyethylene) spacer $(m)$ on the copolymerizability. The apparent reactivities $\left(1 / r_{1}\right)$ of MA-EO $\mathrm{E}_{m}$-HIC- $n$-Ac are lower than for MMA $\left(1 / \mathrm{r}_{1}\right.$ is $c a$. 0.52) and decrease slightly with increasing $m$. The copolymerizability of MA-EO ${ }_{m}$-HIC- $n$-Ac was compared with that of $\alpha$-4-vinylbenzyoxy-ended PHIC macromonomers (VB-HIC- $n-\mathrm{H})$. The decrease in the copolymerizability of the methacrylate-ended PHIC macromonomers is most likely due to the incompatibilities among the macromonomer, comonomer, and propagating polymer chain, together with the fact that methacrylate itself is much more influenced by the polymerization conditions than a styrenic monomer.

KEY WORDS: Poly( $n$-hexyl isocyanate) / Macromonomer / Graft Copolymer / Reactivity Ratio / Copolymerization / Steric Hindrance /
\end{abstract}

Incompatibility / Rodlike Polymer /

Controlling and designing the structure of complex macromolecular architectures have been of tremendous interest to a great number of polymer science researchers. These architectures have often been constructed of macromonomers with a polymerizable functional group at one end. ${ }^{1-3}$ Advances in syntheses using a macromonomer technique have afforded a variety of star-, brush- or comb-shaped polymers via homopolymerization, and graft copolymers by copolymerization with low molecular weight comonomers. ${ }^{4,5}$ A fundamental issue to be considered in a use of macromonomers is their reactivities in co- and homo-polymerization, because this is a key factor in controlling the design of the branched polymers. ${ }^{6}$

The copolymerizabilities of macromonomers are influenced by various factors, ${ }^{7-13}$ including thermodynamic repulsions between the macromonomer and the propagating chain, kinetically excluded volume effects, decreases in the mobility of the reactive species, and properties of the solvent. Among them, the incompatibility is a particularly important factor to be considered when designing graft copolymers showing microphase separation between the grafted chains and the trunk main chain. ${ }^{4,5,14,15}$ The nature of solvent, ${ }^{16,17}$ the total concentration of monomers, ${ }^{18}$ the molar ratio of monomers ${ }^{19}$ and the molecular weight of macromonomers ${ }^{15}$ have also been pointed out as factors affecting the copolymerizability.
In general, the reactivity of macromonomers is known to be similar to or less than that of the corresponding low molecular weight monomer, at least in an apparently homogeneous solution. Ito and his coworkers showed a noticeable decrease in the reactivity of the macromonomer in the copolymerization of methacrylate-ended poly(methyl methacrylate) (PMMA) macromonomer with stearyl methacrylate in benzene ${ }^{20}$ and in the copolymerization of 4-vinylbenzyl- and methacryloyloxyended poly(ethylene oxide) (PEO) macromonomers with styrene. $^{16}$

We have recently reported the syntheses of 4-vinylbenzyloxy- and 2-methacryloyloxyethoxy-terminated rodlike PHIC macromonomers (VB-HIC- $n$-H and MA-EO $1-\mathrm{HIC}-n-\mathrm{H}$, where $n$ is the degree of polymerization of HIC), their fundamental radical copolymerization behavior and many molecular characterization details. ${ }^{21-24}$ In the radical copolymerization of MA-EO 1 -HIC- $n$-H $\left(\mathrm{M}_{2}\right)$ with MMA $\left(\mathrm{M}_{1}\right)$, the apparent reactivity of the macromonomer $\left(1 / \mathrm{r}_{1}\right)$ relative to MMA decreased down to $c a$. 0.6. In remarkable contrast, the reactivity of VB-HIC- $n$-H was almost equivalent to that of styrene (ST). Our interest focuses on the remarkable difference in copolymerizability between a terminal methacrylate and a styrenic group attached to the same PHIC rod. An intuitive explanation for this difference is that a methacrylate group is much more subject to steric hindrance effects from the rigid rod 


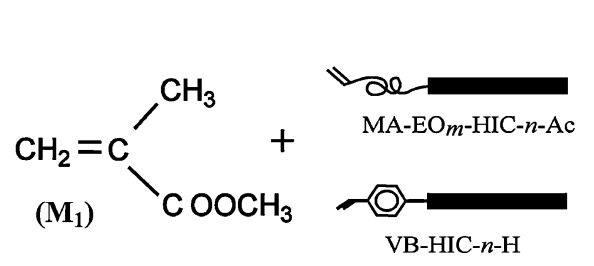

$\left(\mathbf{M}_{2}\right)$

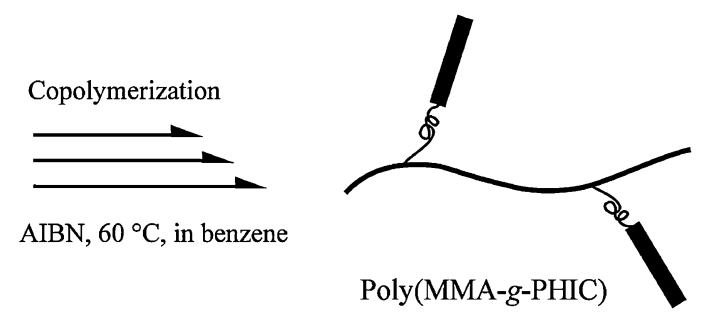

Poly(MMA-g-PHIC)

Scheme 1. Copolymerization reaction scheme of MMA $\left(M_{1}\right)$ with PHIC macromonomers $\left(M_{2}\right)$.<smiles>C=C(C)C(=O)OCCO</smiles>

( $m=1,2,4.5$ and 8 )

Oligo(oxyethylene) Methacrylate
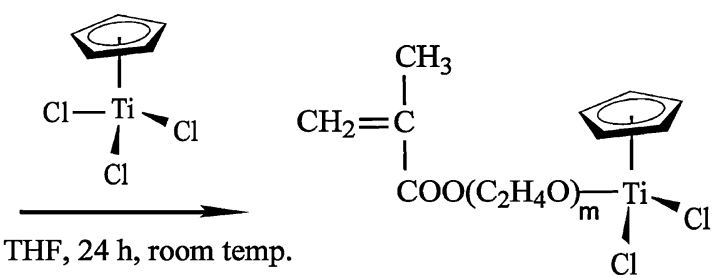

MA-EOm-CpTiCl2

Scheme 2. Reaction scheme of titanium alkoxide complex $\mathrm{MA}-\mathrm{EO}_{\mathrm{m}}-\mathrm{CpTiCl}_{2}$.

than a styrenic group. ${ }^{22}$ If a flexible oligo(oxyethylene) chain is introduced as a spacer between the methacrylate group and the rod, the steric hindrance effects may be reduced or moderated, resulting in the increase of the reactivity.

Herein, we report the preparation of a series of novel poly $(n-$ hexyl isocyanate) macromonomers having an $\alpha$-oligo(oxyethylene) methacrylate and an $\omega$-acetyl-group (MA-EO $\mathrm{m}_{\mathrm{m}} \mathrm{HIC}$ $n$-Ac). We present many details concerning the radical copolymerization behavior of MA-EO $-\mathrm{HIC}-n$-Ac with MMA in order to discuss the influence of a flexible oligo(oxyethylene) spacer on the reactivity of the methacrylate functional group, as shown in Scheme 1.

\section{EXPERIMENTAL}

\section{Materials}

$n$-Hexyl isocyanate (HIC) (Tokyo Kasei, Japan), dichloromethane (Kanto Kagaku Co. Ltd., Japan), acetic anhydride (Kanto Kagaku Co. Ltd., Japan), methyl methacrylate (Wako, Japan), and triethylamine (Kanto Kagaku Co. Ltd., Japan) were distilled from calcium hydride (Kanto Kagaku Co. Ltd., Japan) under reduced pressure just before use. Benzene (Kanto Kagaku Co. Ltd., Japan) was washed with concentrated $\mathrm{H}_{2} \mathrm{SO}_{4}$, neutralized with sodium hydroxide solution, then dried with calcium chloride and finally distilled from $\mathrm{Na}$ /benzophenone. Tetrahydrofuran (THF) (Kanto Kagaku Co. Ltd., Japan) was distilled from Na/benzophenone. 2-Hydroxyethyl methacrylate (HEMA) (Tokyo Kasei, Japan) was distilled under reduced pressure just before use. $\omega$-Hdroxyoligo(oxyethylene) methacrylates $(m=2,4.5,8)$ (The Nippon Oil \& Fats Co. Ltd., Japan) were purified by an azeotropic distillation with toluene, then evaporated, dried under vacuum for $48 \mathrm{~h}$. 2-2'-Azobis(isobutyronitrile) (AIBN) (Wako, Japan) was purified by recrystallization three times from methanol. Boron trifluoride- diethyl etherate $\left(\mathrm{BF}_{3} \mathrm{OEt}_{2}\right)$ (Kanto Kagaku Co. Ltd., Japan), Trichloro(cyclopentadienyl) titanium(IV) $\left(\mathrm{CpTiCl}_{3}\right)$ (Kanto Kagaku Co. Ltd., Japan), Na (Wako, Japan), benzophenone (Wako, Japan), and THF (spectroscopic grade, Wako, Japan) were used as received.

\section{Synthesis of Titanium (IV) Alkoxide Complex (MA-EO ${ }_{m}$ - $\mathrm{CpTiCl}_{2}$ )}

The initiator, $\mathrm{MA}-\mathrm{EO}_{m}-\mathrm{CpTiCl}_{2}$ was prepared according to the method of Novak ${ }^{25,26}$ as described in Scheme 2. The details have been described in previous papers. ${ }^{22,27}$ The reaction was carried out using a three-necked $50 \mathrm{~mL}$ flask equipped with a tube containing dry triethylamine to trap $\mathrm{HCl}$ gas. In a dry box, to a solution of $\mathrm{CpTiCl}_{3}(1.00 \mathrm{~g}, 4.56 \mathrm{mmol})$ in $5 \mathrm{~mL}$ dry THF, a solution of $\omega$-hydroxy-oligo(oxyethylene) methacrylate (MA$\left.\mathrm{EO}_{m}-\mathrm{H}\right)(m=1,2,4.5,8)(4.56 \mathrm{mmol})$ in dry THF was slowly added for $30 \mathrm{~min}$. The flask then was taken out of the dry box and the reaction was carried out at room temperature for $24 \mathrm{~h}$ under $\mathrm{N}_{2}$ atmosphere. After the reaction, THF was evaporated from the reaction mixture by a vacuum pump. The product was dissolved again in a $30 \mathrm{~mL}$ of dry benzene and freeze-dried under reduced pressure. The products were obtained as an yellow powder $(m=1)$ or highly viscous yellow liquids ( $m=2,4.5$, and 8 ). The yield is $85-99 \%$.

\section{Preparation of MA-EO ${ }_{m}$-HIC-n-Ac Using MA-EO ${ }_{m}^{-}$ $\mathrm{CpTiCl}_{2}$}

The reaction scheme of polymerization is shown in Scheme 3. The polymerization of HIC was carried out in a drybox; details of the procedure are described in previous papers. ${ }^{21,22,27}$ In brief, MA-EO ${ }_{m}-\mathrm{CpTiCl}_{2}$ and dichloromethane were added to a $20 \mathrm{~mL}$ flask fitted with a magnetic stir bar. After the initiator was completely dissolved, a desired amount of HIC was added, the flask was sealed off and taken out of the 


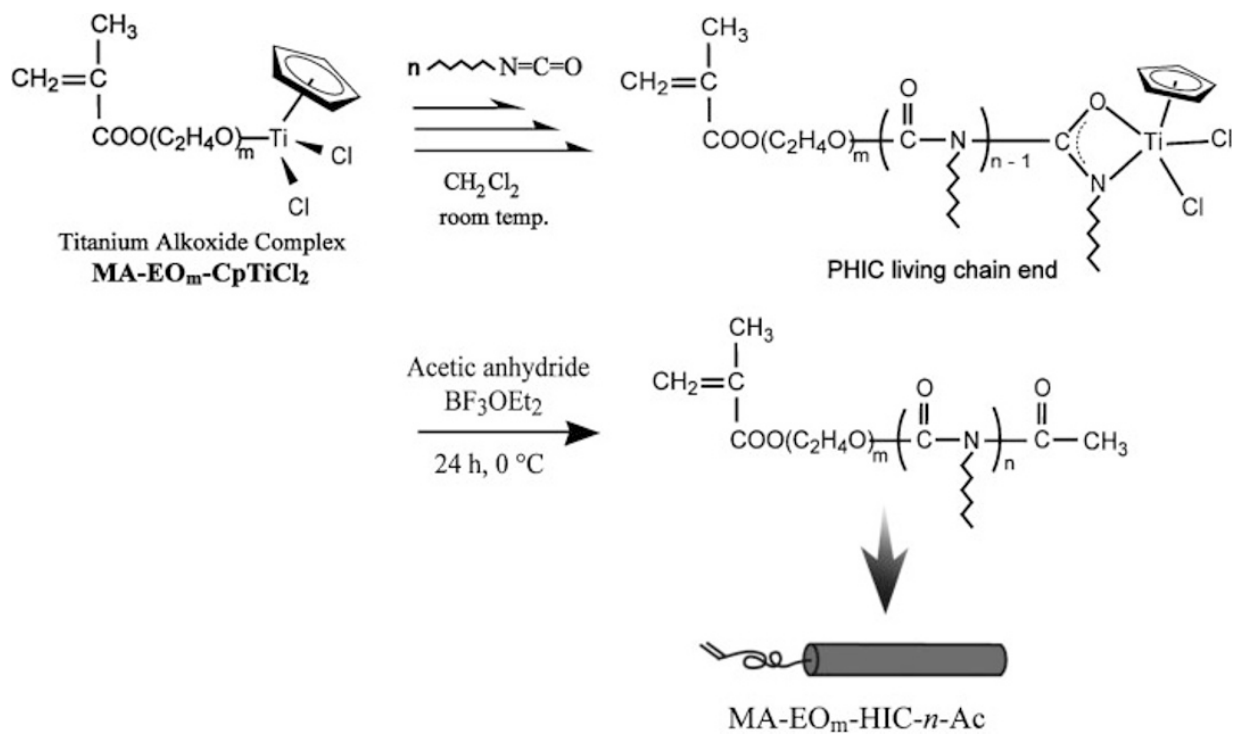

Scheme 3. Reaction scheme of PHIC macromonomers (MA-EO ${ }_{m}-\mathrm{HIC}-n-\mathrm{Ac}$ ).

dry box. The polymerization was carried out at room temperature for $18 \mathrm{~h}$ under the dark. After the polymerization, the solution containing of a large excess amount of acetic anhydride as a terminator and $\mathrm{BF}_{3} \mathrm{OEt}_{2}$ as a catalyst was added to the solid reaction mixture. ${ }^{27}$ The solid body was pulverized in the reaction mixture to disperse it. The dispersion was vigorously stirred for $24 \mathrm{~h}$ at room temperature. After the reaction, the polymer dispersion was slowly poured into methanol at $-5{ }^{\circ} \mathrm{C}$. The polymer was redissolved into THF containing 5\% methanol and reprecipitated into methanol. This procedure was done three times and the polymer was finally freeze-dried from benzene solution. The conversion of HIC was determined by the weight method. 4-Vinylbenzyloxyended macromonomer, VB-HIC- $n-\mathrm{H}$ was prepared according to the procedure reported in previous paper. ${ }^{21}$

\section{Radical Copolymerization of MMA with MA-EO ${ }_{m}-\mathrm{HIC}-n-$ Ac}

The radical copolymerizations of MMA $\left(\mathrm{M}_{1}\right)$ with MA$\mathrm{EO}_{m}$-HIC- $n$-Ac $\left(\mathrm{M}_{2}\right)$ were carried out in benzene at $60^{\circ} \mathrm{C}$. The desired amounts of MMA, MA-EO $m$-HIC- $n$-Ac, benzene and AIBN ( $1 \mathrm{~mol} \%$ to total monomers) were added into a $20 \mathrm{~mL}$ flask and degassed by three times freeze-thawing cycles. The concentrations of MMA and macromonomer are $3.90 \mathrm{~mol} / \mathrm{L}$ and $3.0-12.3 \mathrm{mmol} / \mathrm{L}$, respectively. After the copolymerization, the reaction mixture was poured into a large amount of methanol, filtered and then dried under reduced pressure for $24 \mathrm{~h}$. The conversion of MMA was determined by the weight method using an equation: ${ }^{22}$

Conversion $(M M A)(\%)=\frac{W_{\mathrm{t}}-W_{0}(\text { Macromonomer })}{W_{0}(\text { MMA })} \times 100$

where $W_{0}(i)$ is the weight of component $i$ in a feed and $W_{\mathrm{t}}$ is the weight of the reaction mixture recovered after polymerization time $t$. Unreacted macromonomer from the reaction mixtures was completely removed by washing with $n$-hexane, followed by 5 -times reprecipitation from THF into $n$-hexane. This procedure is especially important for the determination of reactivities in the copolymerization. The complete removal of unreacted macromonomers without missing the resulting graft copolymers (less than $2 \%$ ) was confirmed by ${ }^{1} \mathrm{H}$ NMR and SEC-UV-MALS-RI measurements of $n$-hexane-soluble part and precipitates.

\section{Determination of Copolymerization Parameters}

Copolymerization behavior of the conventional monomer $\left(\mathrm{M}_{1}\right)$ with macromonomer $\left(\mathrm{M}_{2}\right)$ is usually discussed on the basis of the well-known copolymerization equation, MayoLewis equation using the experimental data obtained at very low conversion,

$$
\frac{\mathrm{d}\left[\mathrm{M}_{1}\right]}{\mathrm{d}\left[\mathrm{M}_{2}\right]}=\frac{\left[\mathrm{M}_{1}\right]\left(r_{1}\left[\mathrm{M}_{1}\right]+\left[\mathrm{M}_{2}\right]\right)}{\left[\mathrm{M}_{2}\right]\left(r_{2}\left[\mathrm{M}_{2}\right]+\left[\mathrm{M}_{1}\right]\right)}
$$

Where $\left[\mathrm{M}_{\mathrm{i}}\right]$ is the monomer concentration of component $\mathrm{i}$ in a feed, $r_{\mathrm{i}}=\mathrm{k}_{\mathrm{ii}} / \mathrm{k}_{\mathrm{ij}}$ is the monomer reactivity ratio of $\mathrm{M}_{\mathrm{i}}$, and $\mathrm{k}_{\mathrm{ij}}$ is the propagating rate constant of a propagating chain ending in $\mathrm{M}_{\mathrm{i}}$ reacting with the $\mathrm{M}_{\mathrm{j}}$, with $\mathrm{i}$ or $\mathrm{j}=1$ or 2 . With the condition of $\left[\mathrm{M}_{1}\right] /\left[\mathrm{M}_{2}\right] \gg 1$, the $r_{1}$ determined implies simply the relative reactivities of $M_{1}$ and $M_{2}$ in the competition reaction with the $\mathrm{M}_{1}$-ended radical which is approximated to a homopoly $\left(\mathrm{M}_{1}\right)$ radical. Therefore, the relative reactivity of the macromonomer $\left(\mathrm{M}_{2}\right)$ can be regarded as the reciprocal of $r_{1}, 1 / r_{1}$. Accordingly, eq 2 may be approximated to a simplified form, ${ }^{12}$

$$
\frac{\mathrm{d}\left[\mathrm{M}_{1}\right]}{\mathrm{d}\left[\mathrm{M}_{2}\right]}=r_{1} \frac{\left[\mathrm{M}_{1}\right]}{\left[\mathrm{M}_{2}\right]}, r_{1}=\frac{k_{11}}{k_{12}}
$$

\section{Measurements}

${ }^{1} \mathrm{H}$ NMR spectra were recorded on a JEOL $400 \mathrm{MHz}$ NMR instrument using $\mathrm{CDCl}_{3}$ or $\mathrm{C}_{6} \mathrm{D}_{6}$ as a solvent. 


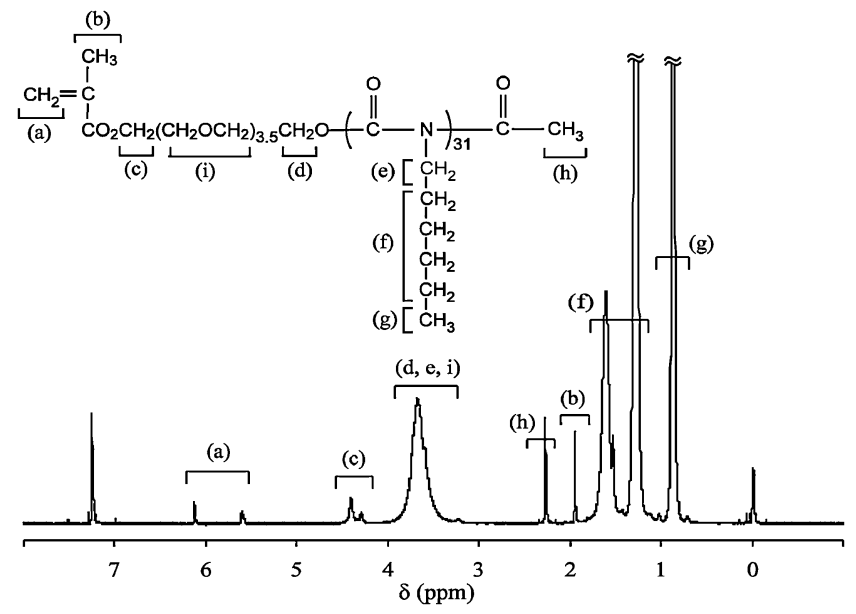

Figure 1. ${ }^{1} \mathrm{H}$ NMR spectrum of $\mathrm{MA}-\mathrm{EO}_{4.5}-\mathrm{HIC}-31-\mathrm{Ac}$ macromonomer in $\mathrm{CDCl}_{3}$ (Table I, Run 9).

The molecular weight and molecular weight distribution of the macromonomers were determined by size exclusion chromatography (SEC; THF, $40^{\circ} \mathrm{C}$, columns: Shodex KF802 + KF806L + KF806L + KF806L, RI; Shodex RI101, UV; Tosoh UV-8020) fitted with a multi-angle laser light scattering detector (DAWN-DSP; wavelength, $632.8 \mathrm{~nm}$, Wyatt Technology) (SEC-UV-MALS-RI) using a series of PHIC standards. Apparent molecular weight of the graft copolymers is determined by SEC-UV-MALS-RI.

Specific refractive index increment $(d n / d c)$ for the macromonomers in $\mathrm{THF}$ at $25^{\circ} \mathrm{C}$ was measured using a differential refractometer (Otsuka Electronics DRM-1021, wavelength; $\lambda=632.8 \mathrm{~nm}$ ) and listed in Table II.

\section{RESULTS AND DISCUSSION}

\section{Preparation of MA-EO ${ }_{m}$-HIC- $n$-Ac Macromonomers}

Figure 1 shows a typical ${ }^{1} \mathrm{H}$ NMR spectrum of $\mathrm{MA}^{-E^{-}}{ }_{4.5^{-}}$ HIC-31-Ac in $\mathrm{CDCl}_{3}$. It shows ${ }^{1} \mathrm{H}$ NMR signals due to the vinyl protons (a) and methyl protons (b) of the $\alpha$-methacryloyloxy group and methyl protons (h) of the $\omega$-acetyl end group $(\delta=2.30 \mathrm{ppm})$ as well as protons from the PHIC chain $(\mathrm{e}, \mathrm{f}, \mathrm{g})$, implying a successful preparation. $\omega$-Acetyl-end-functionality $\left(f_{\omega}\right)$ is calculated from the ${ }^{1} \mathrm{H}$ NMR peak intensity ratio of (h) to (a) by the following equation: ${ }^{27}$

$$
f_{\omega}=\frac{2(\mathrm{~h})}{3(\mathrm{a})} \times 100
$$

The number-averaged molecular weight of the macromonomers, $M_{\mathrm{n}}(\mathrm{NMR})$ is determined from the ${ }^{1} \mathrm{H}$ NMR spectrum by:

$$
M_{\mathrm{n}}(N M R)=n \times M_{\mathrm{HIC}}+M_{\text {endgroup }}
$$

with

$$
n=\frac{2(g)}{3(a)}
$$

where $\mathrm{M}_{\mathrm{HIC}}$ is the molecular weight of $\mathrm{HIC}$ and $\mathrm{M}_{\text {endgroup }}$ is the sum of the molecular weights of the $\alpha$ - and $\omega$-end groups.

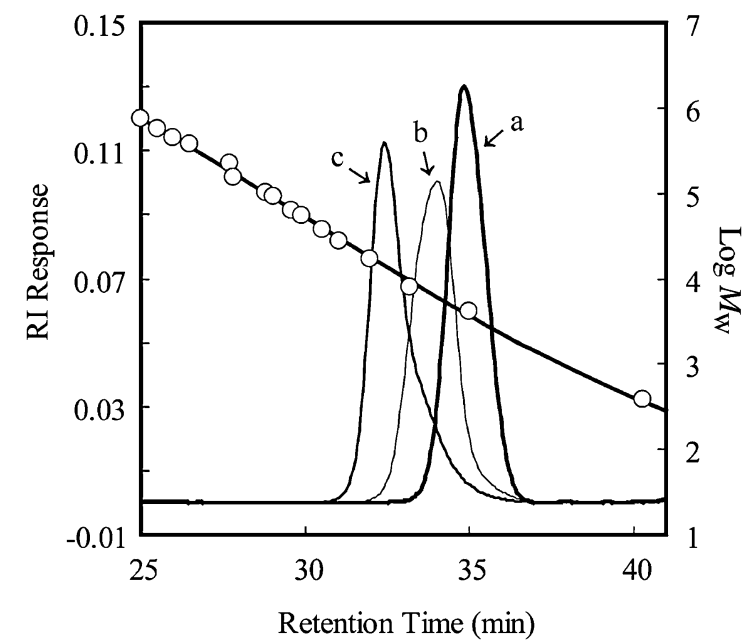

Figure 2. SEC curves of MA-EO $1-H I C-n-A c$ (a) $n=34$, (b) $n=53$ and (c) $n=91$, together with PHIC calibration curve.

Typical SEC curves of MA-EO 1 -HIC- $n$-Ac with $n=34$ (a), $n=53$ (b), and $n=91$ (c), together with the PHIC calibration curve are presented in Figure 2. The polymerization conditions and characteristics of the macromonomers synthesized are summarized in Table I. PHIC macromonomers with a relatively narrow molecular weight distribution are successfully prepared in moderate yield, except for those with $n<40$. The low yield is most likely due to a low reprecipitation efficiency into methanol ${ }^{22}$ and/or that depolymerization by back-biting occurs during termination. ${ }^{27}$ Disagreement between $[\mathrm{HIC}]_{\mathrm{o}} /$ [Ini] and $n(\mathrm{NMR})$ is seen and is caused by low initiator efficiencies and/or depolymerization during termination. Of note on this table, however, is the fact that the values of $M_{\mathrm{n}}$ determined from the ${ }^{1} \mathrm{H}$ NMR peak intensities based on an $\alpha$ methacrylate terminal group are almost identical to the number averaged molecular weight $\left(M_{\mathrm{n}}\right)$ determined by SEC calibrated with a series of PHICs, except for MA-EO $\mathrm{B}_{8}$-HIC- $n$-Ac with a flexible octa(oxyethylene) chain. In addition, an $\omega$-end acetyl group can be quantitatively introduced $\left(f_{\omega}=100 \%\right)$. These results support the successful preparation of PHIC macromonomers having an $\alpha$-oligo(oxyethylene) methacrylate and an $\omega$-acetyl group (MA-EO $\mathrm{m}_{\mathrm{m}} \mathrm{HIC}-n-\mathrm{Ac}$ ).

\section{Copolymerization of MMA $\left(M_{1}\right)$ with MA-EO ${ }_{m}-\mathrm{HIC}-n-A c$ $\left(\mathbf{M}_{2}\right)$}

As discussed above, a critical point in estimating the extent of radical copolymerizability of the macromonomer is the development of a method to remove only unreacted macromonomer from the reaction mixtures, because contamination by the macromonomer significantly affects the results. The complete removal has been effected by washing with $n$-hexane, followed by five cycles of reprecipitation from THF into hexane, a good solvent for PHIC but a non-solvent for graft polymers. The complete removal of unreacted PHIC macromonomer from the reaction mixture is ultimately confirmed using a UV detector in SEC-MALS because the PHIC side chain absorbs UV whereas the PMMA chain does not. A 
Table I. Characteristics of MA-EO $m-\mathrm{HIC}-n-\mathrm{Ac}$ macromonomers prepared by living coordination polymerization of $\mathrm{HIC}^{\mathrm{a})}$

\begin{tabular}{|c|c|c|c|c|c|c|c|c|c|c|}
\hline \multirow{2}{*}{ Run } & \multirow{2}{*}{ Sample } & \multirow{2}{*}{$\frac{[\mathrm{HIC}]_{0}}{[\mathrm{Ini}]_{0}}$} & \multirow{2}{*}{$\frac{\mathrm{CH}_{2} \mathrm{Cl}_{2}}{(\mathrm{~g})}$} & \multirow{2}{*}{$\frac{\left.\text { Yield }^{b}\right)}{(\%)}$} & \multirow{2}{*}{$n^{\mathrm{c})}$} & \multirow{2}{*}{$\begin{array}{l}f_{\omega}^{\mathrm{d})} \\
(\%)\end{array}$} & \multirow{2}{*}{$\frac{M_{\mathrm{n}} \times 10^{-3}}{(\mathrm{NMR})^{\mathrm{e})}}$} & \multirow{2}{*}{$\frac{M_{\mathrm{w}} \times 10^{-3}}{\left.\mathrm{SEC}^{\mathrm{f}}\right)}$} & \multirow{2}{*}{$\frac{M_{\mathrm{w}} / M_{\mathrm{n}}}{\mathrm{SEC}^{\mathrm{f})}}$} & \multirow{2}{*}{$\frac{\mathrm{dn} / \mathrm{dc}}{(\mathrm{mL} / \mathrm{g})}$} \\
\hline & & & & & & & & & & \\
\hline 1 & $M A-E O_{1}-H I C-31-A c$ & 18.9 & 1.22 & 65.5 & 31 & 100 & 4.12 & 4.08 & $1.1_{7}$ & $0.082_{4}$ \\
\hline 2 & $\mathrm{MA}-\mathrm{EO}_{1}-\mathrm{HIC}-34-\mathrm{Ac}$ & 25.2 & 0.72 & 88.1 & 34 & 99.3 & 4.50 & 4.09 & $1.0_{8}$ & $0.084_{1}$ \\
\hline 3 & $\mathrm{MA}-\mathrm{EO}_{1}-\mathrm{HIC}-53-\mathrm{AC}$ & 44.0 & 0.57 & 96.2 & 53 & 99.2 & 6.91 & 6.88 & $1.1_{3}$ & $0.084_{3}$ \\
\hline 4 & MA-EO 1 -HIC-91-Ac & 77.2 & 0.49 & 95.4 & 91 & 100 & 11.7 & 12.9 & $1.2_{1}$ & $0.083_{7}$ \\
\hline 5 & $\mathrm{MA}-E \mathrm{O}_{2}-\mathrm{HIC}-33-\mathrm{Ac}$ & 25.0 & 0.98 & 66.7 & 33 & 100 & 4.41 & 3.89 & $1.0_{9}$ & $0.085_{1}$ \\
\hline 6 & $\mathrm{MA}-\mathrm{EO}_{2}-\mathrm{HIC}-45-\mathrm{Ac}$ & 42.5 & 0.82 & 80.3 & 45 & 100 & 5.94 & 5.39 & $1.1_{2}$ & $0.085_{1}$ \\
\hline 7 & $\mathrm{MA}-\mathrm{EO}_{2}-\mathrm{HIC}-75-\mathrm{Ac}$ & 71.0 & 0.71 & 97.2 & 75 & 100 & 9.75 & 10.1 & $1.2_{0}$ & $0.085_{6}$ \\
\hline 8 & $\mathrm{MA}-\mathrm{EO}_{2}-\mathrm{HIC}-78-\mathrm{Ac}$ & 51.0 & 3.12 & 72.3 & 78 & 100 & 10.1 & 7.67 & 1.27 & - \\
\hline 9 & $\mathrm{MA}-\mathrm{EO}_{4.5}-\mathrm{HIC}-31-\mathrm{Ac}$ & 26.0 & 1.43 & 50.4 & 31 & 100 & 4.27 & 3.29 & $1.0_{9}$ & $0.083_{8}$ \\
\hline 10 & $\mathrm{MA}-\mathrm{EO}_{4.5}-\mathrm{HIC}-42-\mathrm{Ac}$ & 44.0 & 1.26 & 82.2 & 42 & 100 & 5.67 & 4.80 & $1.1_{6}$ & $0.084_{1}$ \\
\hline 11 & MA-EO $4.5-\mathrm{HIC}-65-\mathrm{Ac}$ & 73.0 & 0.99 & 94.4 & 65 & 100 & 8.59 & 8.18 & $1.3_{0}$ & $0.085_{1}$ \\
\hline 12 & MA-EO $8-H I C-55-A C$ & 24.0 & 2.20 & 70.1 & 55 & 100 & 7.51 & 4.63 & $1.1_{2}$ & - \\
\hline 13 & $\mathrm{MA}-\mathrm{EO}_{8}-\mathrm{HIC}-74-\mathrm{Ac}$ & 49.6 & 1.28 & 89.6 & 74 & 100 & 9.93 & 7.70 & $1.2_{1}$ & $0.083_{2}$ \\
\hline 14 & MA-EO $8-H I C-109-A c$ & 79.7 & 0.68 & 93.8 & 109 & 100 & 14.4 & 12.0 & $1.3_{1}$ & $0.084_{2}$ \\
\hline 15 & VB-HIC-33-H & 20.1 & 2.70 & 61.7 & 33 & - & 4.33 & 4.21 & $1.1_{2}$ & - \\
\hline 16 & VB-HIC-56-H & 29.4 & 1.50 & 93.2 & 56 & - & 7.23 & 8.04 & $1.1_{6}$ & - \\
\hline 17 & VB-HIC-77-H & 59.4 & 1.00 & 89.9 & 77 & - & 9.91 & 10.8 & $1.2_{1}$ & - \\
\hline
\end{tabular}

a) Polymerization was carried out under $\mathrm{N}_{2}$ atmosphere at room temperature. ${ }^{b}$ Conversion of HIC was determined by the weight method. ${ }^{c}$ Degree of polymerization of $\mathrm{HIC}(n)$ determined by the ${ }^{1} \mathrm{H}$ NMR spectrum using eq 6 . ${ }^{d)}$ Functionality of acetyl ended group determined from the ${ }^{1} \mathrm{H}$ NMR spectrum using

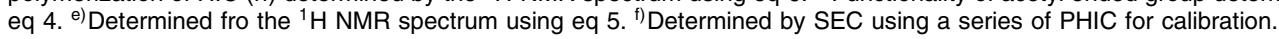

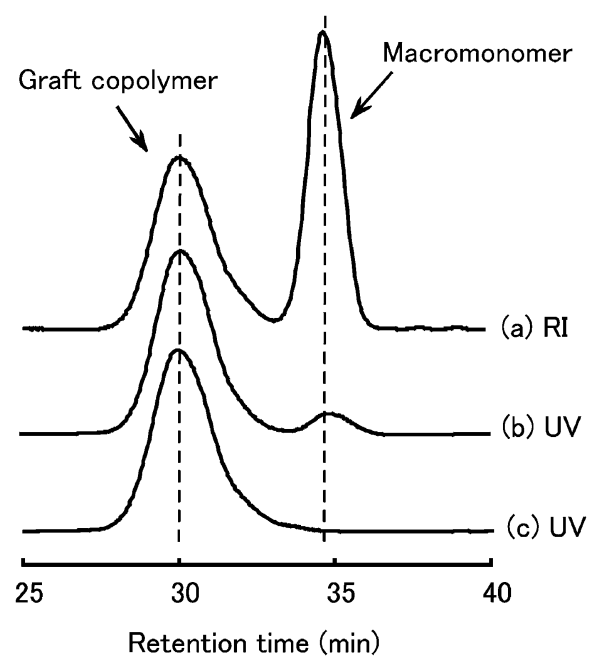

Figure 3. SEC curves before and after removal of unreacted macromonomer from the reaction mixture: (a) RI signals of poly(MMA- $g$-PHIC) copolymer and unreacted PHIC macromonomer, (b) UV signals of mixture after washing with $n$-hexane, and (c) UV signals of poly(MMA-g-PHIC) copolymer.

representative SEC-UV-MALS-RI curve is presented in Figure 3 where (a) is the RI signal of the reaction mixture of graft copolymer and macromonomer, (b) is the UV signal of the sample after washing with $n$-hexane and (c) is the UV signal of the isolated graft copolymer by following the reprecipitations. Complete removal of unreacted PHIC macromonomer is apparent.

Figure 4 shows a typical ${ }^{1} \mathrm{H}$ NMR of the isolated PMMA- $g$ $\mathrm{P}\left(\mathrm{MA}-\mathrm{EO}_{2}-\mathrm{HIC}-78-\mathrm{Ac}\right)$ in $\mathrm{C}_{6} \mathrm{D}_{6}$. From the NMR peak intensity ratio of (b) to (a), $\alpha=(\mathrm{b}) /(\mathrm{a})$, the composition of the graft copolymer, $d\left[M_{1}\right] / d\left[M_{2}\right]$ was calculated using eq 7 for the corresponding $m$ value:

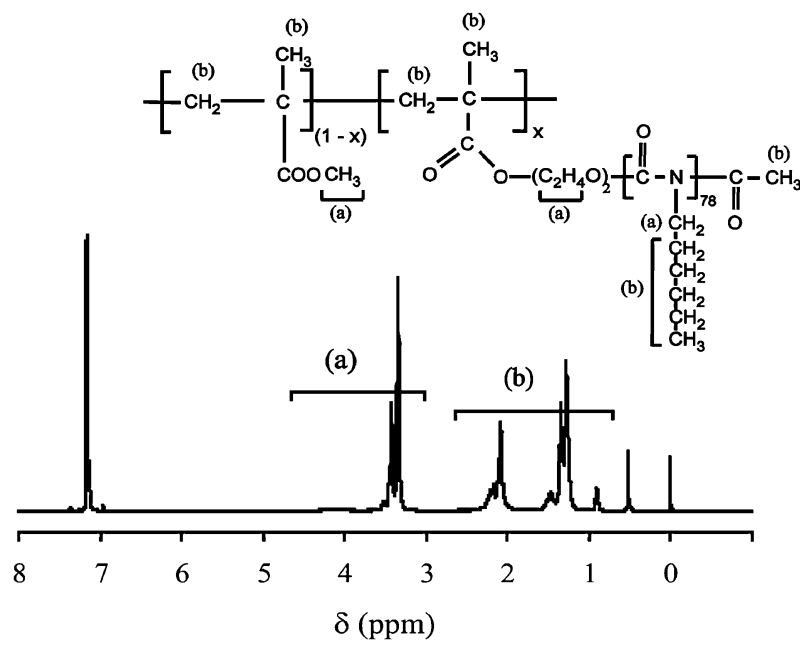

Figure 4. ${ }^{1} \mathrm{H}$ NMR spectrum of graft copolymer, poly(MMA- $g-M A-E O_{2}-\mathrm{HIC}$ 78-Ac) in $\mathrm{C}_{6} \mathrm{D}_{6}$

$$
\frac{\mathrm{d}\left[\mathrm{M}_{1}\right]}{\mathrm{d}\left[\mathrm{M}_{2}\right]}=\frac{(2 \mathrm{n}+4 \mathrm{~m}) \alpha-(11 \mathrm{n}+8)}{5-3 \alpha}
$$

where $m$ and $n$ are the degrees of polymerization of oxyethylene and HIC, respectively. The copolymerizabilities of all the macromonomers listed in Table I were examined and the represetative copolymerization results are listed in Table II. The apparent $M_{\mathrm{n}}(\mathrm{app})$ of the graft copolymers was determined by SEC-MALS with $d n / d c=0.085 \mathrm{~mL} / \mathrm{g}$ both for PMMA and PHIC macromonomer and is presented in Table II. The apparent degree of polymerization of the main chain $(D p(a p p))$ and the apparent number of branched chains $(f(a p p))$ of the graft copolymers are also listed in Table II, by the equations: ${ }^{22}$ 
Table II. Copolymerization results of MMA $\left(\mathrm{M}_{1}\right)$ with MA-EOm-HIC- $n-A c\left(\mathrm{M}_{2}\right)$ and with VB-HIC- $n-\mathrm{H}\left(\mathrm{M}_{2}\right)^{\mathrm{a})}$

\begin{tabular}{|c|c|c|c|c|c|c|c|c|}
\hline \multirow{2}{*}{ Sample run } & {$\left[\mathrm{M}_{1}\right]$} & Conv. $\left(\mathrm{M}_{1}\right)$ & $\mathrm{d}\left[\mathrm{M}_{1}\right]^{\mathrm{b})}$ & \multirow{2}{*}{$1 / r_{1}$} & \multirow{2}{*}{$1 / r_{1}$ (av.) } & \multirow{2}{*}{$\frac{M_{\mathrm{n}}(a p p)^{\mathrm{c})}}{\left(\times 10^{-5}\right)}$} & \multirow{2}{*}{$\frac{D p(a p p)^{\mathrm{d})}}{\left(\times 10^{-3}\right)}$} & \multirow{2}{*}{$f(a p p)^{d)}$} \\
\hline & {$\left[\mathrm{M}_{2}\right]$} & $(\%)$ & $\mathrm{d}\left[\mathrm{M}_{2}\right]$ & & & & & \\
\hline \multicolumn{9}{|c|}{$M A-E O_{1}-H I C-34-A c$} \\
\hline 1 & 602 & 6.04 & 1223 & 0.49 & \multirow{3}{*}{$0.51 \pm 0.04$} & 1.40 & 1.36 & 1.05 \\
\hline 2 & 494 & 5.83 & 1005 & 0.49 & & 1.37 & 1.32 & 1.28 \\
\hline 3 & 268 & 5.35 & 489 & 0.55 & & 1.42 & 1.42 & 2.62 \\
\hline \multicolumn{9}{|c|}{$\mathrm{MA}-\mathrm{EO}_{2}-\mathrm{HIC}-75-\mathrm{Ac}$} \\
\hline 1 & 902 & 8.42 & 1676 & 0.53 & \multirow{5}{*}{$0.55 \pm 0.02$} & 1.36 & 1.33 & 0.78 \\
\hline 2 & 615 & 7.88 & 1131 & 0.54 & & 1.39 & 1.34 & 1.18 \\
\hline 3 & 651 & 8.58 & 1172 & 0.56 & & 1.31 & 1.27 & 1.08 \\
\hline 4 & 796 & 8.43 & 1441 & 0.55 & & 1.32 & 1.29 & 0.89 \\
\hline 5 & 739 & 8.16 & 1341 & 0.55 & & 1.34 & 1.30 & 0.97 \\
\hline \multicolumn{9}{|c|}{ MA-EO $4.5-\mathrm{HIC}-42-\mathrm{Ac}$} \\
\hline 1 & 637 & 8.28 & 1385 & 0.45 & \multirow{4}{*}{$0.49 \pm 0.04$} & 1.13 & 1.09 & 0.77 \\
\hline 2 & 406 & 8.00 & 797 & 0.50 & & 1.23 & 1.16 & 1.43 \\
\hline 3 & 516 & 8.15 & 1076 & 0.48 & & 1.11 & 1.06 & 0.98 \\
\hline 4 & 318 & 7.84 & 610 & 0.51 & & 1.13 & 1.05 & 1.70 \\
\hline \multicolumn{9}{|c|}{$\mathrm{MA}-\mathrm{EO}_{8}-\mathrm{HIC}-55-\mathrm{AC}$} \\
\hline 1 & 614 & 6.03 & 1442 & 0.40 & \multirow{4}{*}{$0.40 \pm 0.01$} & 1.55 & 1.51 & 0.97 \\
\hline 2 & 491 & 6.21 & 1117 & 0.42 & & 1.59 & 1.52 & 1.29 \\
\hline 3 & 343 & 5.35 & 782 & 0.40 & & 1.62 & 1.53 & 1.78 \\
\hline 4 & 410 & 6.22 & 923 & 0.40 & & 1.49 & 1.42 & 1.39 \\
\hline \multicolumn{9}{|l|}{ VB-HIC-77-H } \\
\hline 1 & 2989 & 7.83 & 2887 & 1.04 & \multirow{3}{*}{$1.06 \pm 0.03$} & 1.45 & 1.39 & 0.48 \\
\hline 2 & 1982 & 8.17 & 1817 & 1.09 & & 1.34 & 1.25 & 0.69 \\
\hline 3 & 1493 & 8.61 & 1402 & 1.07 & & 1.62 & 1.47 & 1.05 \\
\hline
\end{tabular}

a) Representative results are listed in this table. ${ }^{\text {b) }}$ Determined by ${ }^{1} \mathrm{H}$ NMR peak intensity ratio of (a) to (b) peaks shown in Figure 3 using eq 7 . ${ }^{c}$ Determined by SEC-MALS and using eqs 8 and 9 . d) Calculated using eqs 8 and 9.

$$
\begin{aligned}
D p(a p p) & =\frac{M_{\mathrm{n}}(a p p)(y+1)}{M_{1}(y+k)} \\
f(a p p) & =\frac{D p(a p p)}{y+1}
\end{aligned}
$$

where $\mathrm{y}=\mathrm{d}\left[\mathrm{M}_{1}\right] / \mathrm{d}\left[\mathrm{M}_{2}\right], \mathrm{k}=\mathrm{M}_{2} / \mathrm{M}_{1}$, and $M_{\mathrm{i}}$ is the monomer molecular weight of species $i$. It is seen in this Table that the apparent reactivity $\left(1 / \mathrm{r}_{1}\right)$ of MA-EO ${ }_{m}$-HIC- $n$-Ac is lower than MMA and almost independent of the flexible oxyethylene length $(m)$, slowly decreasing with increasing $m$.

Figure 5 shows all the experimental data concerning the apparent reactivity $\left(1 / \mathrm{r}_{1}\right)$ of the $\mathrm{MA}-\mathrm{EO}_{m}-\mathrm{HIC}-n$-Ac macromonomers $\left(\mathrm{M}_{2}\right)$ relative to $\operatorname{MMA}\left(\mathrm{M}_{1}\right)$, plotting $1 / \mathrm{r}_{1}$ against the degree of polymerization of $\operatorname{HIC}(n)$. For $n \geq 30$, molecular weight dependence of the $1 / \mathrm{r}_{1}$ value is not observed within experimental error, and $1 / \mathrm{r}_{1}$ ranges from 0.40 to 0.54 . This value is slightly smaller than that for $\omega$-hydrogen terminated MA-EO $\mathrm{E}_{1}$-HIC- $n$-H ( $\left.c a .0 .6\right)$, reported in previous$1 \mathrm{y},{ }^{22}$ whose $\omega$-terminal amide groups form hydrogen bonding with each other in benzene. No noticeable $m$ - or $n$-dependency of the reactivity of the macromonomers is observed. Rather, the $1 / \mathrm{r}_{1}$ value seems to slightly decrease with increasing $m$. This result suggests that the decrease in reactivity of a methacrylate group attached to the rod does not come from steric hindrance effects. Two explanations for the low reactivity are the solubility of the comonomer with the PHIC chain, and incompatibilities between MMA and PHIC chains.

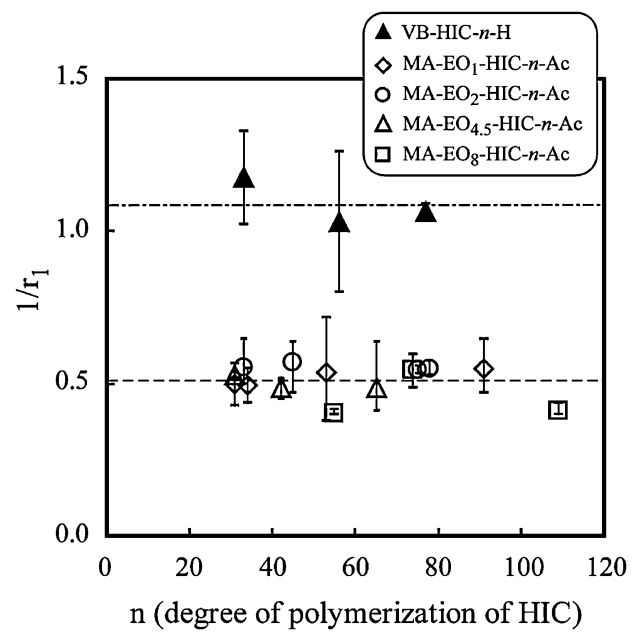

Figure 5. Plots of apparent relative reactivity $\left(1 / r_{1}\right)$ vs degree of polymerization of HIC $(n)$ in the copolymerization of MMA $\left(\mathrm{M}_{1}\right)$ with MA$\mathrm{EO}_{m}$-HIC- $n-\mathrm{Ac}\left(\mathrm{M}_{2}\right)(m=1(\diamond) ; 2(\bigcirc) ; 4.5(\triangle)$ and $8(\square))$ and with VB-HIC- $n$-II $\left(\mathrm{M}_{2}\right)(\mathbf{\Delta})$.

With regard to the solubility difference between ST and MMA toward the PHIC chain, ST can dissolve the PHIC chain whereas MMA cannot. While the copolymerizations were carried out in benzene, the repulsion between MMA and the PHIC chain may result in a microscopic increase in the concentration of MMA around a propagating PMMA chain. With respect to the incompatibilities, the character of the monomers may be considered to be parallel to that of polymer. 
Table III. Summary of the radical copolymerizability of PHIC macromonomers with MMA or ST

\begin{tabular}{|c|c|c|c|c|}
\hline $\begin{array}{l}\text { Macromonomer } \\
\qquad\left(\mathrm{M}_{2}\right)\end{array}$ & $\begin{array}{c}\text { Comonomer } \\
\qquad\left(\mathrm{M}_{1}\right)\end{array}$ & $\begin{array}{c}1 / r_{1} \\
\text { (observed) }\end{array}$ & $\begin{array}{c}1 / r_{1} \\
(\text { expected })^{a)}\end{array}$ & Notes \\
\hline MA-EO $m-\mathrm{HIC}-n-\mathrm{Ac}$ & MMA & $0.56-0.40$ & 1.0 & decrease \\
\hline $\mathrm{MA}-\mathrm{EO}_{1}-\mathrm{HIC}-n-\mathrm{H}$ & MMA & $0.60^{22}$ & 1.0 & decrease \\
\hline $\mathrm{MA}-\mathrm{EO}_{1}-\mathrm{HIC}-n-\mathrm{H}$ & ST & $1.2-1.4$ & 1.9 & decrease $^{22}$ \\
\hline VB-HIC-n-H & MMA & 1.1 & 2.2 & decrease \\
\hline VB-HIC-n-H & ST & 1.1 & 1.0 & same $^{21}$ \\
\hline
\end{tabular}

a) The value expected for the copolymerization between low molecular weight monomers; that is, $r_{1}=1.0$ for the copolymreization of $\operatorname{MMA}\left(M_{1}\right)$ with $\operatorname{MMA}\left(M_{2}\right)$ and $S T\left(M_{1}\right)$ with $S T\left(M_{2}\right) ; r_{1}=0.46$ and $r_{2}=0.52$ in the copolymerization of $M M A\left(M_{1}\right)$ with ST(M $\left.M_{2}\right)^{28}$

Thus, a PMMA propagating chain is less compatible with a PHIC chain than a PST chain, resulting in larger thermodynamic repulsion between the PMMA and PHIC chains than between PST and PHIC chains. To support these ideas, we further carried out the copolymerization of VB-HIC- $n$-H with MMA in benzene as follows.

\section{Copolymerization of MMA (Mith VB-HIC-n-H}

Table II shows the copolymerization results of MMA $\left(\mathrm{M}_{1}\right)$ and VB-HIC-77-H $\left(\mathrm{M}_{2}\right)$ in benzene at $60^{\circ} \mathrm{C}$ and all experimental data are plotted in Figure 5 . The $1 / \mathrm{r}_{1}$ values range from 1.0 to 1.2 , which are approximately one half of the reference value of $1 / \mathrm{r}_{1}=2.2$ in the copolymerization of $\operatorname{MMA}\left(\mathrm{M}_{1}\right)$ with $\operatorname{ST}\left(\mathrm{M}_{2}\right) .{ }^{28}$ This lowering is similar to that observed in the copolymerization of MMA $\left(\mathrm{M}_{1}\right)$ with MA$\mathrm{EO}_{m}$-HIC- $n$-Ac $\left(\mathrm{M}_{2}\right)$ and may be explained by the same reasoning as above.

\section{Summary of Radical Copolymerizability of Rodlike Macro- monomers}

The relative reactivities $\left(1 / \mathrm{r}_{1}\right)$ of radical copolymerization of methacrylate- and 4-vinylbenzyl-ended rodlike macromonomers with MMA or ST are summarized in Table III, together with the data reported previously. ${ }^{21,22}$ The $1 / \mathrm{r}_{1}$ value of the macromonomer with a methacrylate terminal group always decreases down to about one second of the values found in the radical copolymerization between the low molecular weight monomers, irrespective of the comonomers. On the other hand, the reactivity of the macromonomer with a styrenic group strongly depends on the comonomers. The decrease in the

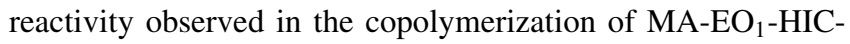
$n$-H with ST is not simply explained by incompatibilities. While not all of the results obtained in the radical copolymerization of the rodlike macromonomers can be fully explained, it can be concluded that the decrease of the reactivity in the radical copolymerization of rodlike macromonomers with $\mathrm{MMA}^{22}$ is due to incompatibility of the macromonomer and comonomer, and that a methacrylate polymerizable group is much more influenced by the polymerization condition than a styrenic group.

\section{CONCLUSIONS}

A series of novel rodlike PHIC macromonomers (MA-EO ${ }^{-}$ HIC- $n$-Ac) having an $\alpha$-oligo(oxyethylene) methacrylate group and an $\omega$-acetyl group have successfully been prepared by living coordination polymerization of $\mathrm{HIC}$, followed by termination with acetic anhydride. The radical copolymerization behavior of MA-EO ${ }_{m}$-HIC- $n$-Ac $\left(\mathrm{M}_{2}\right)$ with MMA $\left(\mathrm{M}_{1}\right)$ has thoroughly been studied and rationalized as a function of $m$ and $n$. The apparent reactivity of the macromonomer $\left(1 / r_{1}\right)$ is not noticeably influenced by $n$ and $m$, and is lower than for MMA $\left(1 / \mathrm{r}_{1}\right.$ is $\left.c a .0 .52\right)$. The decrease in the copolymerizability of the methacrylate-ended macromonomers is due to not steric hindrance from the rod but an incompatibility between the macromonomer and comonomer. The methacrylate group itself is much more influenced by the polymerization condition than the styrenic group.

Acknowledgment. Supported in part by a Grants-in-Aid from the Ministry of Education, Science, Sports and Culture of Japan (16550105) and (19550117), by The Foundation for Japanese Chemical Research, and by the Saneyoshi Scholarship Foundation. We also thank Prof. Masato Suzuki, Nagoya Institute of Technology for helpful discussions.

Received: July 20, 2008

Accepted: August 12, 2008 Published: September 29, 2008

\section{REFERENCES}

1. K. Ito, Prog. Polym. Sci., 23, 581 (1998).

2. K. Ito and S. Kawaguchi, Adv. Polym. Sci., 142, 129 (1999).

3. P. F. Rempp and E. Franta, Adv. Polym. Sci., 58, 1 (1984).

4. W. Radke, S. Roos, H. M. Stein, and A. H. E. Müller, Macromol. Eng., 189 (1995).

5. W. Radke, S. Roos, H. M. Stein, and A. H. E. Müller, Macromol. Symp., 101, 19 (1996).

6. K. Matyjaszewski, J.-F. Lutz, and H. Shinoda, U.S. Patent, 7049373 (2006).

7. Y. Tsukahara, K. Mizuno, A. Segawa, and Y. Yamashita, Macromolecules, 22, 1546 (1989).

8. Y. Tsukahara, K. Tsutsumi, Y. Yamashita, and S. Shimada, Macromolecules, 23, 5201 (1990).

9. K. Ishizu, T. Fukutomi, T. Kakurai, and T. Noguchi, Polym. J., 1, 105 (1973).

10. K. Ishizu, T. Fukutomi, T. Kakurai, and T. Noguchi, Makromol. Chem., 179, 1981 (1978).

11. M. Takaki, R. Asami, and T. Matsuse, Polym. J., 21, 519 (1989).

12. K. Ito, H. Tsuchida, A. Hayashi, T. Kitano, E. Yamada, and T. Matsumoto, Polym. J., 17, 827 (1985).

13. Y. Tsukahara, M. Tanaka, and Y. Yamashita, Polym. J., 19, 1121 (1987). 
14. V. Percec and J. H. Wang, J. Polym. Sci., Part A: Polym. Chem., 28, 1059 (1990).

15. H. Yoshida, S. Itsuno, and K. Ito, Can. J. Chem., 73, 1757 (1995).

16. K. Ito, K. Uchida, T. Kitano, E. Yamada, and T. Matsumoto, Polym. J., 17, 761 (1985).

17. Y. Tsukahara, N. Hayashi, X.-L. Jiang, and Y. Yamashita, Polym. J., 21, 377 (1989).

18. V. Percec and J. H. Wang, Makronol. Chem. Macromol. Symp., 54/ 55, 561 (1992).

19. W. Radke and A. H. E. Müller, Makromol. Chem. Macromol. Symp., 54/55, 583 (1992).

20. K. Ito, N. Usami, and Y. Yamashita, Macromolecules, 13, 216 (1980).

21. M. Kikuchi, S. Kawaguchi, and K. Nagai, Des. Monomers Polym., 7,
603 (2004).

22. S. Kawaguchi, T. Mihara, M. Kikuchi, L. T. N. Lien, and K. Nagai, Macromolecules, 40, 950 (2007).

23. M. Kikuchi, T. Mihara, Y. Jinbo, Y. Izumi, K. Nagai, and S. Kawaguchi, Polym. J., 39, 330 (2007).

24. M. Kikuchi, L. T. N. Lien, A. Narumi, Y. Jinbo, Y. Izumi, K. Nagai, and S. Kawaguchi, Macromolecules, in press.

25. T. E. Patten and B. M. Novak, J. Am. Chem. Soc., 113, 5065 (1991).

26. T. E. Patten and B. M. Novak, Macromolecules, 26, 436 (1993).

27. L. T. N. Lien, M. Kikuchi, A. Narumi, K. Nagai, and S. Kawaguchi, Polym. J., submitted.

28. F. R. Mayo, F. M. Lewis, and C. Walling, J. Am. Chem. Soc., 70, 1529 (1948). 